\title{
ON A NEW METHOD TO CURE CATARACT BY EXTRACTION OF THE LENS* $\dagger \ddagger$
}

\author{
BY \\ JACQUES DAVIEL \\ TRANSLATED BY \\ W. G. PEARCE \\ Western Ophthalmic Hospital, London, N.W.1.
}

IT is well known that the diseases of the eyes and principally the cataract have been little studied, nor shown much success when treated. If one reflects on the frequent misfortunes attached to the surgery of the eyes, it is not surprising that the cataract, so as to say, has been abandoned to empiricism.

The skilful men of the past century have delivered us from the ancient oculists' error concerning the nature of the cataract. They believed it was formed by a membrane made by the thickness of the aqueous humour. But now, one knows that the cataract consists of the opacification of the lens, and as this is a truth that to-day, no-one ignores nor contests, I will not stop to give the evidence for it. The discovery is principally due to the celebrated M. Lasnier, Member of the College of Surgeons of Paris, and not to Master Jan and Brisseau, who essentially confirmed it.

Several writers have written on this illness, but very few have practised the operations that the cataract demands, while only a small number of famous surgeons have applied themselves to it. If I wished to speak the ordinary language of the oculists, I would distinguish numerous species of cataracts, but as these multiple divisions appear useless, I would admit only two of them, a true and a false. The true cataract is an opacity of the lens in its whole or in part. It is necessary that the pupil dilate by a quarter to a half, that the patient distinguish the light from the darkness and that the eye be otherwise healthy. The false cataract or the bad type is an opacity of the lens, accompanied by an immobile pupil, which is either too dilated or too contracted. The patient cannot distinguish the shadow of objects and these symptoms bespeak often enough the true gout which may be accompanied by the severe headaches, persistent ophthalmia, etc.

The ancients who had always looked at the cataract as a membrane, invented means of attacking it, conforming to their opinion. Some employed round needles, around which they imagined themselves to roll this alleged membrane like a ribbon. Others invented needles with extreme points to make less division of the sclera. Others employed those with a cutting edge to divide the strands which, according to them, attached the cataract to the ciliary processes. Finally, Freytagius is the inventor of a type of spring tweezers or forceps terminating in a needle with which he proposes to extract the membranous cataract from the eye.

\footnotetext{
* Originally published in 1753 in Mémoires de l'Académie Royale de Science, vol. 2, p. 337.

+ Received for publication March 9, 1966.

‡ Address for reprints: M.R.C. Population Genetics Research Centre, Old Road, Headington, Oxford. 
In 1745, while working in Marseilles, I suspected that the pointed needles and cutting edges were the cause of the frequent accidents following the usual operation (i.e. couching). I imagined that a needle flat and blunt at the end in the form of a little spatula, if used subsequent to the initial puncture, would be more successful in attacking the cataract. A single experience did not confirm my suspicions. This was followed by an operation that I am now going to relate, as it gave birth to the reflections out of which developed the method that I employ to-day.

A hermit from Aiguille, in Provence, having had an unsuccessful operation on his right eye, came to see me in Marseilles to beg of me to operate on his left and, though reluctant, I consented. After having used an ordinary needle with cutting edges to divide the sclera, I found that I was unable to displace the cataract and broke the lens in the process. It further occurred that several portions of the broken lens passed into the anterior chamber, which then filled with blood, so that my needle was no longer visible. I was then obliged to withdraw it, being unable to complete the operation. This accident determined me in the same way as Monsieur Petit, a to open the transparent cornea and evacuate the blood with the fragments of the cataract which had passed into the anterior chamber. This I did by passing a half-bent needle through the cornea into the chamber. I then enlarged the opening with small curved scissors and by this means, evacuated the contents of the anterior chamber. The iris appeared clean and the patient distinguished immediately the objects which were presented to him. But as his eye had been weakened by the first procedure the second was unsuccessful and was followed two days later by suppuration. The cause of these accidents was, without doubt, the pulling about of the interior membranes and the division of vitreous humour.

This sequence of events made me take the resolution to operate no longer but by opening the cornea as I had done to the hermit and to search for the lens in its setting, in order to make it pass through the pupil into the anterior chamber and then to take it from the eye. I did this operation for the first time on a woman. I opened the cornea as I have explained, then I placed the little spatula, of which I have already spoken, on the superior part of the cataract, which I then detached, and drew in pieces from the eye. The pupil appeared clean. The patient did not have the least accident and was cured 15 days later.

This success encouraged me to continue with this method and it again fared well in four more patients, although apparently failing at several points necessary to perfection. I continued using it, however, on several more patients but it did not produce such happy results. I felt then the necessity to test the new way of operating and to compare these different methods and finally to try if possible to find a way of avoiding the all too frequent accidents. I resolved to practise the traditional cataract operation with two instruments. The first was shaped like a small straight lancet, which served to open the sclera at the usual spot. The second instrument, shaped as a small spatula, was passed through this opening toward the top of the lens, to lie between this body and the posterior part of the iris. I was then able to attack the cataract with facility and promptitude.

A great number of operations were performed by this method, several of which

a M. Petit had practised in 1708 section of the cornea to extract the lens which had dislocated into the anterior chamber. See Mémoires L'Académie Royale des Sciences-année 1708. 
were witnessed by the most distinguished masters of the art. As these were followed with great success, I began to believe that this method was preferable to the others. I was now in a position to test the various instruments and techniques which had been used in performing the traditional operation.

I put into use all the different types of needles. I also practised the operation in different ways; sometimes carrying the needle behind the lens in order to rupture the posterior bed of the lens to place this body in the vitreous humour. At another time, I tried to open the capsule of the lens in its inferior part, to precipitate the cataract into the vitreous humour through this opening. Other times, I attempted to carry the small spatula over the anterior part of the cataract which I then easily pushed down, but I observed that the operation following this last procedure succeeded only when the membrane of the lens was thin and fine. It is not the same when one meets a firm membrane, a soft cataract and the vitreous humour at the same time a little too thick. Then the irritation of the membrane caused by the needle and the divisions necessarily made into the vitreous often caused considerable accidents, sometimes even suppuration in the eye and atrophy of this organ.

Not content with trying all the ways to operate on a cataract, I planned new experiments to examine with precision those derangements of the interior parts of the eye which result from a particular operation done with any particular needle. The result of these observations has been quite different from what I expested. Often there were successful results in which the pupil was clear, the lens was found lying at the bottom of the vitreous, and in which there were no internal derangements. But other times, however, the lens was broken by the needle and fragments passed through the pupil into the anterior chamber. In this case, the more I stirred up the needle in the eye, the less it became clear. Often, I found extreme difficulty in shifting the lens from its bed and finally it once happened to me that I placed it between the retina and the choroid after tearing these membranes in several places.

I doubted no longer that the various derangements I had noticed in the eyes of cadavers were the unfortunate results of surgery. I thought that they depended not only on the introduction of a needle into the eye, whatever type it may be, but also on the resistance of the membrane and the location of the lens after its depression.

As for the form of different needles, one realizes that those which are fine and pointed only prick and, not having enough surface, they are unable to press well on the cataract to depose it into the bottom of the vitreous. They must at least cause those accidents due to the puncture of the delicate parts. In general, the needles which are sharp cut the vessels and often cause the effusions of blood into the eye, which prevent the completion of the operation. Those which are flat, blunt and rounded, can crush and tear the internal membranes of the eye and produce other annoying accidents. Independent of those which may be attributed to the needles, it occasionally happens that the lens causes harm by its presence in different parts of the eye. This depends on the situation that it takes after its depression. Finally, I have omitted altogether those accidents which the most exact operator cannot avoid whatever care he takes. 
In spite of these inconvenient differences, I believed that I must continue with my last method, which consisted of employing a cutting instrument and afterwards a flat needle to press down the cataract, until such time as the ideas deriving from the operation on the hermit had acquired a certain degree of maturity. The event which I am going to relate finished by persuading me.

On April 8, 1747, I was called to see a private individual in whom the cataracts appeared good and the eyes favourable for operation. I started to operate on the left eye, in which the cataract appeared most solid. However, it was not possible for me to attack it. The pupil appeared to squint after the operation and the patient saw absolutely nothing. I passed therefore to the right eye, in which I had much difficulty. Not having been able to push down the cataract from this eye, I decided to open the cornea as I had done to the hermit. After lifting the cornea with small forceps, I then carried my little spatula across the pupil and drew from the posterior chamber of the eye all the lens which had broken in several places during the first operation. This extraction was followed by the loss of a portion of vitreous, which had also been divided by the preceding operation. In spite of this inconvenience, the patient was able to distinguish objects after the operation. No bad aftereffects followed and he was considered cured a little time later.

During the following three years, I practised this operation several times on living subjects, to accustom myself to it. But it was only in the course of a voyage that I made at Mannheim in order to treat Son Altesse Sérénissime, Madame la Princesse Palatine de Deux Ponts, who had an ancient illness in her left eye that I took the resolution henceforth no longer to operate on the cataract but by extraction of the lens.

I had the occasion to visit Liège, and stayed there several days. I performed six operations by this method, with the best of success. One that I did at Cologne on a monk was an even more striking success as the cataract was soft like jelly. However, the monk was in a state to say the Mass 15 days after the operation. Monsieur de Vermale, Associate of the Académie and first surgeon to the Elector Palatine, who saw me perform at Mannheim, has rendered an account of this operation in a printed letter to M. Chicoyneau, first physician of the king. I have continued to practise it in different places and I number as of to-day, November 16, 1752, 206 operations of which 182 have succeeded. It is, I think, a very good account for an operation which has just originated. The details of it follow.

When one has recognized that an eye is attacked by cataract, it matters little for this method as to what nature it is-senile, soft, hard, or what colour, as the operation equally succeeds, provided that the eye is otherwise healthy. For the principal aim of my operation is the extraction of the lens out of its bed, which one easily obtains by the precautions I am going to describe.

I prepare the patient following the usual and known manner. The day determined for the operation I arrange the dressings which consist of bandages, compresses, small pieces of linen, oval plasters made with palm oil, small sponges, pieces of cotton on sticks, hot water and wine. 
The instruments that I employ are (Plate XIX) - a pointed needle, half curved with a cutting edge having the form of a lancet and destined to make the first opening (Fig. 1), a blunt needle, also cutting and half curved to enlarge the same opening (Fig. 2), two pairs of scissors with convex curves (Fig. 3), a little spatula of gold, silver, or steel to turn up the cornea (Fig. 4a), another small needle, pointed and sharp on two sides to open the membrane which anteriorly hides the lens (Fig. 4b), a small curette of gold, silver, or steel to facilitate the issue of the lens or to withdraw the fragments of this body when some of it remains in the pupillary gap; small forceps to carry away portions of the membrane which present themselves. All these instruments will be arranged in order on a plate and placed in the hands of a student who will have care of them, and give them to the surgeon according to his need.

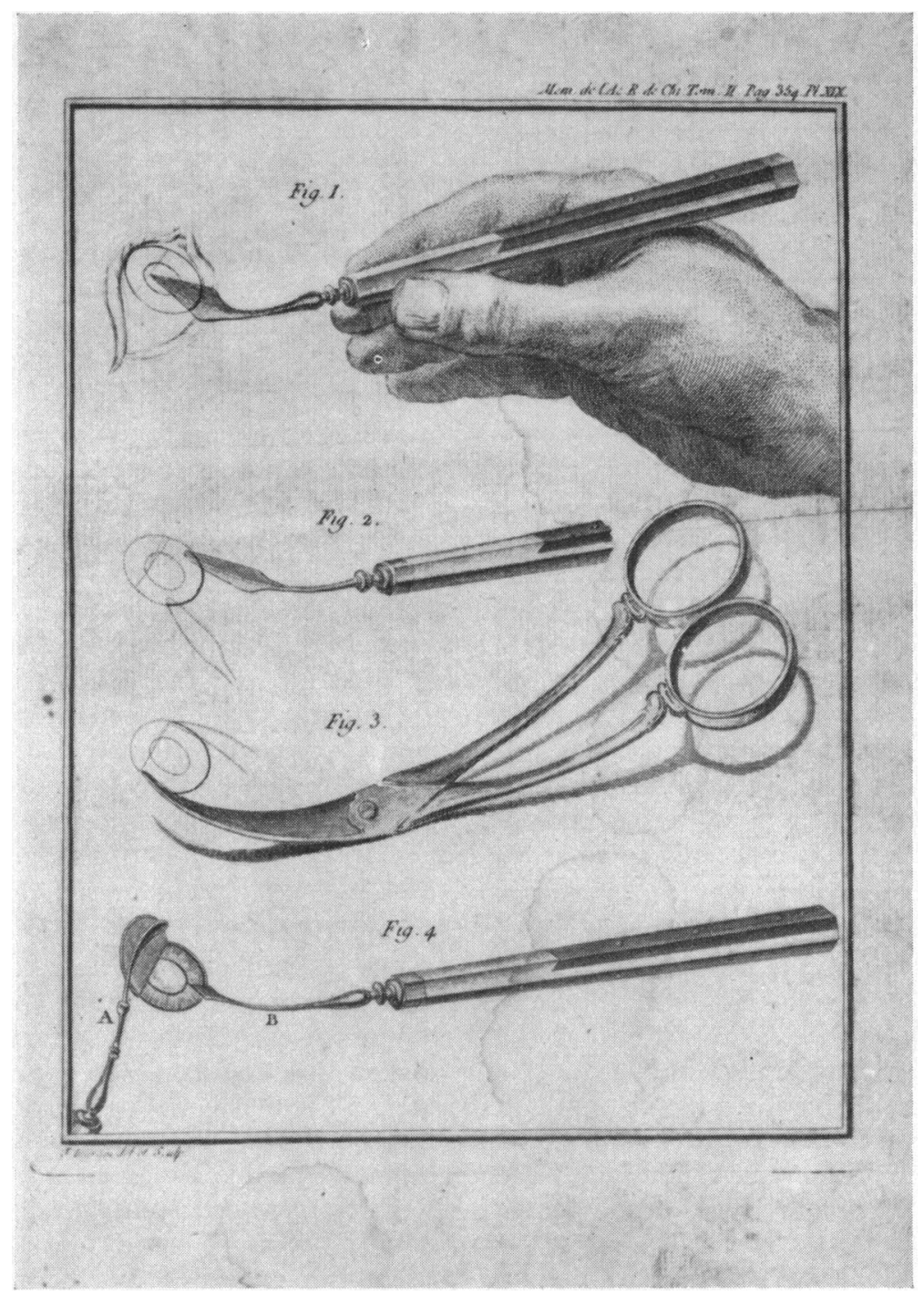


All being laid out in this way, the patient will be placed in a poorly-lighted room in order that the bright daylight will not make the pupil contract, nor after the operation penetrate into the eye with too much force.

The patient will be seated on a low chair, or on a stool. The one who operates will be seated in front of the patient on a chair higher than the patient, in order that in operating, he places his elbows on his knees. He will cover the other eye with a bandage following which a student standing behind the patient places one hand on the forehead, two fingers of which are stretched out on to the upper eyelid. The other hand he places under the chin.

The surgeon lowers the inferior lashes (Plate XXA) and taking the first needle, he plunges it into the anterior chamber near to the sclera, avoids wounding the iris and carries it just above the pupil (XXB). He then withdraws it slowly in order to take the blunt needle with which he widens the initial incision by carrying this instrument to the left and right to open the cornea in the form of a crescent following its curve (CC). But as the cornea is then found a little slack, the surgeon takes the curved convex scissors (D), of which he introduces the blunt blade between this membrane and the iris and completes the section equally on each side (EE), to a little above the pupil. One observes that the curvature of the scissors must look at the globe and being doubly curved two pairs are necessary to accommodate them to the curves on each side of the cornea.

The surgeon then takes the little spatula (F) with which he raises gently the part of the cornea which has been cut $(G)$ and incises with the little pointed and cutting needle $(H)$ the membrane of the lens. Sometimes it is necessary to cut the membrane circularly if it be thick and wrinkled and to take it away entirely, for fear it plugs up the pupil. When the membrane is well cut, it can be taken away with the little forceps.

After having cut the membrane which envelops the lens, care is taken to carry the little spatula between this body and the iris, to detach the cataract absolutely and to facilitate its issue. The vault of the cornea falls back, completing this part of the operation. It is then that the surgeon has need of all his prudence, since it concerns the drawing of the veil which hides the light. It is then necessary to press the globe of the eye gently without tiring it (See the applied fingers (II)). By this method, one avoids rupture of the posterior membrane of the lens which serves to dam and prevent the escape of vitreous humour. It is with pleasure that the pupil is seen to enlarge little by little and the lens having once presented its bevelled edge slides gently into the anterior chamber and from there over the cheek. Then the pupil appears clear, the cloud which covered the eye is dispersed and the patient formerly plunged into darkness sees again the light with as much astonishment as satisfaction. One re-establishes the pupil which is occasionally deranged by the escape of the lens. This is especially so when the lens is hard and solid or of a large volume.

The operation completed, care is necessary to prevent the impression of bright daylight on the eye.

If it occurs that the cataract be soft and glaireous, or broken, that which remains can be removed by employing a little curette that the surgeon carries around the pupil as many times as will be necessary. After that, the canopy of the cornea is exactly replaced. The eye is then wiped gently with a little sponge soaked in luke-warm water, and mixed in several drops of spirit of wine or ophthalmic water. The plasters are applied over a little ball of cotton and held with a bandage that is not too tight. The head is covered with a towel, and the patient lies down in a darkened room, if possible, on his back, and in a bed with drawn curtains. The eye is fomented with an emollient or resolutive 2-3 times a day and as frequently as one believes necessary. Aside from remembering the possibility of bleeding, and providing an exact diet, the patient is managed according to the usual customs. 


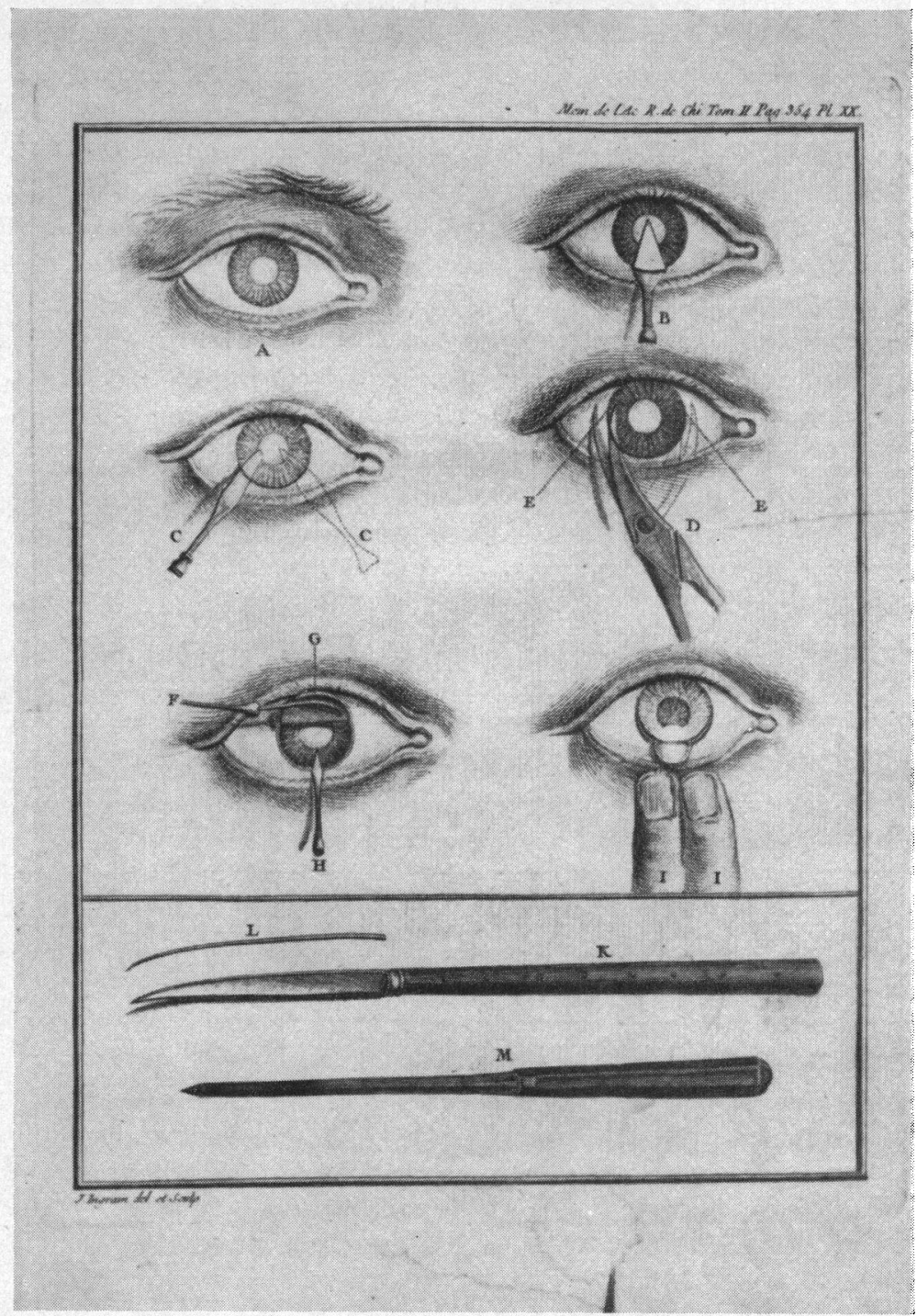

What preference do I believe one must give to this manner of operating? I agree that it has its special accidents. There are those that one can prevent or anticipate. For example, during the operation a portion of the vitreous humour can flow out of the eye but one is almost sure to avoid it by pressing only lightly on the globe when extruding the lens. There are cases where it appears necessary to employ a stronger pressure. If the membrane of the lens is adherent to the iris, then this adherence is destroyed with a spatula and the pupil prepared little by little for the exit of the lens. If it occurs that some blood overflows into the anterior chamber through a wound in the iris, it easily runs out through the incision and that does not in any manner impede the operation. This accident has not happened to me for a long time-since performing the operation in the presence of Monsieurs Le Dran, Morand, La Faye, and several others-when the eye did not appear too 
bad and the patient saw as perfectly with it as with the other which was operated on immediately afterwards.

Though all the aqueous humour escapes over the operative field, it is only an inconvenient necessity and is without consequence, but if one withdraws too quickly the needle destined to open the cornea, the iris can follow the aqueous humour and be found nipped between the two lips of the little wound. It is easy to disengage it by raising the cornea with the little spatula, and sometimes even the natural movements of the eye make it return.

In the course of the treatment, the iris can still escape through the incision and form a staphyloma, but it is easy to remedy this by making the iris go back and one is almost sure to avoid it by dressing the eye without squeezing it with the bandage, as this accident is ordinarily only the result of too tight pressure.

I think that one will agree that the accidents of which I have just spoken are truly little things in comparison to those which can happen after the usual operation. These are not just the sole advantages of the method, the most notable of which seem to be:

(1) In operating by the ancient method, it is necessary to wait until the cataract becomes solid, and often, it does not become so. Here the cataract can be extracted from the outset and without waiting for its maturity.

(2) When it is solid the cataract can reascend even long after the best-performed operation, and it cannot be denied that this accident happens occasionally. Here, on the contrary, one is sure that the cataract removed from the eye does not reascend.

(3) By the ordinary method, the cataract occasionally passes in whole or in part through the pupil into the anterior chamber. This may happen in the days immediately following the operation, or many years later. As the cornea is not open, the lens becomes a foreign body in the anterior chamber, which can be very disagreeable and even bring about the loss of the eye, or at least demand another operation. Following my method, the cataract is drawn entirely out of the eye after passing through the pupil.

(4) While performing the ordinary method on a soft cataract, the operation often becomes imperfect by the fragments of the torn membranes, or by blockage of the pupil with several portions of the lens. This places a similar obstacle to the rays of light as the entire cataract. By my method, the soft lens is removed which prevents this occurring. I have also taken away those lenses which resemble hydatids, and have detached those which are adherent to the iris.

(5) In order to attack the cataract by the ancient method, it is necessary to traverse the vitreous humour and one often tears membranes by the repetitive movements of the needle. This it is not possible to do without serious consequence. It is also not possible to avoid this by employing a needle without a point or a cutting edge. It is easy to see that this accident can have no place in my method.

I believe I have said enough to prove the excellence of this method and the preference which it merits over the others. It has had the votes of the masters of the art, before whom I have operated and several have already adopted it. It only remains for me to prove that I am the inventor of this operation, over which someone appears (I do not know through which motive) to wish to dispute with me the discovery.

The ancients had all put forward that a cataract was a membrane formed in the anterior chamber from the aqueous humour. It is only since 1656, in the manner that 
I have remarked at the commencement of this thesis, that one recognized that a cataract consisted of the opacity of the lens. It is, therefore, useless to search among those authors for the method of extracting the cataractous lens. One will object perhaps that the ancients, knowing of the membranous cataract, had imagined the extraction of the membrane and that this is proven by the works of several Arab authors, such as Avicenna and Rhasis. It is not difficult to reply to this:

(1) If one supposes this operation to have been practised, it would only be the membranous cataract which would have been the object of it, and that does nothing to diminish the merit of the extraction of the lens, which introduces quite different ideas.

(2) While admitting the passage from Avicenna that M. Thurant (Bachelor of Medicine of the Faculty of Paris) cites in his thesis sustained in 1752 on the extraction of the lens, one can oppose nothing which takes away from me the merit of the invention. Here is the text of Avicenna:

Et homines vias habent diversas in exercendo curam aquae, quae fit cum instrumento, ita ut quidem fint, qui disrumpant inferiorem partem corneae, $\mathrm{E}$ extrahant aquam per eam; $\mathrm{E}$ hoc est in quo est timor, quoniam cum aqua quando est grossa, egreditur humor albugineus.

\section{Thurant then continues as follows:}

Aqua apud Avicennam idem est ac suffusio, hypochyma. Grossam dicit cataractam duriorem.

Now, in examining this text, one does not find the description of the cataract such as we know it, and even if I grant that Avicenna had heard about the cataractous lens and its extraction, has he left us expressly the manner to do this operation? Have I not the glory to have revived it and to have published the way to practise it?

It is, therefore, no longer necessary to pay regard to the testimony of the authors who have spoken of the extraction of the cataract. I only know two of them-M. Freitag and M. Heister.

The first had seen only the membranous cataract and he had been partly refuted by M. Heister, who placed in doubt his operation. The second (M. Heister) said in his "Surgery" Part IIE, Section 2E, Chapter 55, Page 578, that "it has been reported to him that Mr. Taylor, an English oculist, had boasted 'gloriatum esse', of having pulled out the adherent cataracts behind the uvea through a wound made in the cornea". M. Heister, adding nothing more, informed the public only of a hearsay and of a possibility. It is true M. Thurant adds to this text of M. Heister that Mr. Taylor had actually performed this operation several times in the year 1737, but $\mathrm{I}$ fear that it is only a gratuitous allegation and I believe myself able to give proof of this.

Mr. Taylor, being at Vienna in Austria in 1750, had operated in the presence of the celebrated M. Van-Sweiten, Member of this Academy, and one would not suspect Mr. Taylor of negligence to leave M. Van-Sweiten unaware of the singular operations that he had done. M. Van-Sweiten certainly would have been informed. Nevertheless in a letter of April, 1751, in reply to that of M. de Vermale, he not only makes no mention of Mr. Taylor, but after having agreed that, in following my method, one avoids the disadvantages of the usual operation he adds the following:

"The unrivalled difficulty is to be able to deliver the lens, especially when it is most rigid and of a considerable volume. For it then appears to me that one must do some violence to the iris, especially in those people who have this opening most narrow and 
little dilatable. Nevertheless, the multiplicity of happy successes of the operation makes all the difficulties vanish that one can set against it, and a skilful hand brings to a successful conclusion those things which appear most difficult to others".

If M. Van-Sweiten had seen this operation practised by Mr. Taylor and even by some others, he would not have made a response so precise.

This great doctor is not the only one who has paid honour to my method. I must add here the favourable report that M. Welken, Doctor of S.A.S. (Son Altesse Sérénissime) the Elector Palatine, has made for him and the testimony of $\mathbf{M}$. Mauchard, Professor of Medicine at Tubingen, and first physician to the Duke of Wurtenberg and, without contradiction, the most famous oculist in all Germany.

I await from the public the justice that I have every reason to hope for, and I think it not possible to do better in order to reconcile me to this justice than to place my discovery in the annals of the Academy.

I finish by warning that this Mémoire is only, properly speaking, an extract of that which I hope to publish on this matter in a complete treatise on the diseases of the eyes. 